\title{
VIAJE AL SUEÑO SOCIALISTA
}

\author{
Sylvia Eyzaguirre
}

Centro Estudios Públicos

\begin{abstract}
iajes a las estepas, del historiador Cristián Pérez, narra la aventura de jóvenes campesinos chilenos de izquierda, que parten en plena época de la Unidad Popular a la Unión Soviética, a efectos de formarse en el manejo y mecánica de maquinaria agrícola, durante tres años, para luego volver a Chile a colaborar con el proyecto socialista insertándose en la producción agrícola nacional. Son noventa y tres jóvenes comprometidos con el país, la gran mayoría de ellos también con la causa comunista y la construcción de una nueva sociedad. Sin embargo, a los pocos días de llegar a su destino, tiene lugar el golpe de Estado en Chile, que cambia para siempre el curso de sus vidas. Ésta es la historia olvidada de estos hombres. Pero también, en parte, es la historia de la derrota del proyecto político del socialismo y de toda una generación que vivió esa épica refundacional.
\end{abstract}

El primer aspecto notable de este libro es el esfuerzo de su autor por rescatar esta historia, que había quedado en el olvido. La historia es como un tejido, que se construye con cientos de miles de hebras. Por lo general, para entender momentos importantes de aquélla nos detenemos en las hebras más gruesas, ésas que son más vistosas, pero son las miles

Sylvia Eyzaguirre. Doctora en filosofía por la Universidad de Friburgo. Investigadora del Centro de Estudios Públicos. Email: seyzaguirre@cepchile.cl. 
de hebras que componen el tejido las que le dan la textura, densidad y color. Pérez toma noventa y tres delgadas hebras, prácticamente invisibles, del tejido histórico que fue la Unidad Popular, y a través de ellas reconstruye la épica y la mística de ese momento en Chile. La historia de estos hombres es una ventana para mirar desde otro ángulo el proyecto socialista de la Unidad Popular, para entender el espíritu de esa época y conocer cómo fue la vida en el exilio.

El libro, muy bien documentado, comienza con una breve contextualización de la situación política de Chile en la década del setenta. En breves páginas, Pérez relata los principales acontecimientos internacionales y nacionales antes y durante la Unidad Popular, los cuales explican las cien becas que ofrece Leonid Brezhnev a Salvador Allende para formar campesinos en el uso de maquinaria agrícola. El texto continúa su curso explicando cómo se realizó la selección de los campesinos, su venida a Santiago, el largo viaje a la Unión Soviética y el aún más largo viaje hasta su destino final, en las estepas rusas. Luego, Pérez relata cómo vivieron los estudiantes el golpe militar chileno en la Unión Soviética y cómo tuvieron que continuar sus vidas lejos de sus familias, sin noticias de ellas y sin poder regresar. Finalmente, el autor decide concentrarse en la vida de seis jóvenes que son llevados a Bulgaria para recibir entrenamiento militar. Aquí se abre otra puerta de la historia de Chile; a saber, la historia de la resistencia. Cinco de estos jóvenes son enviados a Cuba y luego a Nicaragua para combatir en la guerrilla. Una vez que regresan de Cuba son enviados a Chile para luchar contra la dictadura. El libro termina en el presente, contándonos qué fue de estos chilenos que quedaron atrapados en la Unión Soviética.

En 126 páginas muy bien escritas, Pérez va cruzando las hebras de la vida de los jóvenes con acontecimientos políticos de la época, todo muy bien documentado sirviéndose de registros y testimonios. El libro no sólo se queda en los acontecimientos políticos relevantes: éstos son complementados con detalles sabrosos de la vida de nuestros protagonistas, que sin duda amenizan la lectura. No se puede dejar de mencionar la cuota de humor que tiene el relato, sacando a relucir la picardía tan propia del chileno. Un buen ejemplo es cuando los chilenos deben lidiar con la policía rusa a causa de los enfrentamientos a golpes con los jóvenes rusos del pueblo, que estaban celosos de las relaciones sentimentales entre los chilenos y las jóvenes rusas. El autor nos cuenta que: 
Aunque las autoridades debían sancionarlos por los actos reñidos con la ley soviética, las ordenanzas muchas veces se topaban con el "ingenio" de los latinos, quienes evitaron los castigos refugiándose en la honestidad de los rusos. Si un grupo de rusos y chilenos era detenido por estar ebrios peleando en las afueras de la Casa de la Cultura y se les interrogaba por separado en el cuartel, los locales admitían que ellos habían tomado y estaban peleando, mientras que los chilenos negaban ambos hechos. (...) "Eso nos salvó muchas veces, especialmente cuando les habíamos pegado a los rusos", reconoce Alberto Reyes. ${ }^{1}$

Otro ejemplo se ve cuando los cinco jóvenes que hicieron el entrenamiento militar en Bulgaria cantaban al marchar canciones como "Alicia va en el coche, Carolín" o la del spot publicitario "Sabrosito", que era una marca de productos de cerdo, para reírse de sus superiores búlgaros. El autor nos cuenta que:

Los jefes búlgaros, que no entendían nada de español, pensaban que eran canciones revolucionarias y fomentaban la iniciativa, que se mantuvo hasta que el general director de la escuela les anunció la presencia del ministro de Defensa de Bulgaria (...) y les pidió que entonaran esas canciones cuando el alto jefe pasara revista. Entonces, cundió la preocupación, porque el ministro podía llegar con traductores al español y, en lugar de ser felicitados, serían castigados. Se vieron obligados a dejar de divertirse con esas niñerías y cantar algo mucho más comprometido con la revolución, como el himno de los partisanos italianos antifascistas durante la Segunda Guerra Mundial "Bella ciao" ("Adiós, linda”), que sí cumplía con los estándares. (103)

Pero si hubiera que elegir un adjetivo para este libro, creo que lo adecuado sería decir que es un libro nostálgico. El autor, a través de la vida de estos jóvenes, recrea el espíritu que hizo posible la Unidad Popular: un mundo lleno de esperanza donde lo colectivo es más grande que lo personal, donde la revolución traería por fin justicia social, un nuevo orden en el mundo para un nuevo hombre. Esa mística, ese idealismo, el autor lo mantiene presente en casi todo el libro, a pesar de

${ }^{1}$ Cristián Pérez, Viajes a las estepas (Santiago: Catalonia-UDP, 2018), 65. En lo que sigue, este libro se cita tan sólo con su número de página entre paréntesis. 
las desfavorables condiciones de nuestros protagonistas. Sólo al final, cuando nos cuenta en qué devino cada una de estas personas, observamos que la magia se ha extinguido.

Pérez logra mantener la mística, porque elige concentrarse precisamente en aquellos jóvenes más comprometidos con la causa política; en particular, en aquellos cinco jóvenes que, después de sus estudios en Akhtyrskiy, son llevados a Bulgaria sin su consentimiento, para ser allí entrenados militarmente y, más tarde, luchar contra la dictadura de Pinochet. Son cada una de estas historias llenas de épica y mística las que tiñen de nostalgia el relato.

Pero la nostalgia no sólo radica en la selección de los personajes y en las historias que decide relatar el autor, sino también en el narrador, quien participa activamente de este relato, enfatizando las hazañas de los protagonistas y defendiéndolos de las injusticias que sufrieron. Aquí no estamos frente a un narrador imparcial, aparentemente objetivo, propio de la academia. En cada línea de la narración se respira el compromiso de Pérez con la causa de aquel entonces y, cómo no, con los protagonistas de esta historia. El narrador aparece repetidas veces en el texto para recordarnos lo difícil de las circunstancias en que viven estos campesinos, para llamar nuestra atención sobre las proezas que realizan, aplaudir sus logros y tratar con cariño asuntos menos ejemplares como las riñas con los rusos o los altercados con la policía. Así, este narrador no se conforma únicamente con narrar, sino que también opina. Por ejemplo, no titubea ni un segundo en defender a Raúl Cantillana y criticar la actual burocracia del Estado chileno en lo que respecta a la convalidación de títulos, culpando de ello a la dictadura militar.

De este modo, un ingeniero agrónomo formado en una de las mejores universidades dedicadas al tema en el mundo se perdió por lo engorroso de las normativas y la desconfianza con el mundo socialista, una herencia de los 17 años de dictadura militar que aún se mantiene. (121-122)

Me temo, sin embargo, que la burocracia del Estado de Chile tiene larga data, mucho más antigua que la dictadura militar.

Otro comentario en esta línea es la crítica que hace el narrador al diario nacional La Tercera de la Hora por su falta de objetividad. Sin duda, como nos muestra Pérez, el reportaje que publica este periódico 
tergiversa la historia de estos jóvenes campesinos que se encuentran estudiando en la Unión Soviética, manipulando los hechos. Pero, al mismo tiempo, el autor no desliza ningún comentario negativo a la falta de libertad de prensa que había en la Unión Soviética, que asumo era similar a la que existía en Chile en dictadura, ni de la cantidad de burocracia en aquella unión de repúblicas, de la cual son víctimas nuestros protagonistas, ni a la falta de libertad para desplazarse por el territorio soviético.

El autor no emite juicios sobre hechos que hoy -y supongo que en aquel entonces también - resultan sumamente coercitivos. Para ofrecer una muestra: los jóvenes que no pasaron la prueba de idioma después de seis meses estudiando ruso no pudieron formarse en mecánica agrícola y fueron enviados a otras partes a estudiar o, de frentón, a trabajar, incumpliendo el compromiso inicial de la beca. En ese mismo sentido, el texto nunca efectúa una crítica al proyecto socialista o al régimen totalitario soviético. De hecho, en un pasaje el narrador nos dice:

Sin proponérselo, en los días inmediatamente posteriores al golpe militar, los jóvenes campesinos se convirtieron en activistas de la solidaridad y resistencia del pueblo chileno en Europa. De ahí en adelante, los akhtyrskiyanos - como se llamaban entre ellos- cumplieron un importante papel participando en cuanta actividad antidictatorial se hizo dentro de los límites de la Unión Soviética. (61)

Como si la Unión Soviética estuviera lejos de ser un régimen totalitario.

Este libro no se agota en el retrato de una época y de un proyecto político, es también un relato de la fortaleza humana. Más allá de las anécdotas políticas y los acontecimientos históricos que tuvieron lugar, lo más relevante de este libro es la proeza de estos jóvenes, que provenían de familias campesinas de pocos recursos económicos, que salieron adelante en condiciones muy duras: lejos de su tierra, sin información sobre sus familias, sin saber si las volverían a ver, en un país con un clima crudo y un idioma difícil. Es un relato de sobrevivencia y 
superación, y uno como lector no puede sino sentir admiración y empatía por cada uno de estos hombres. Esta historia nos muestra cómo jóvenes de escasos recursos pueden salir adelante cuando se les entregan oportunidades. Todos aprendieron ruso, prácticamente la mitad estudió en el liceo técnico de Akhtyrskiy y muchos de ellos siguieron estudios superiores: economía, medicina, ingeniería forestal. Todos ellos son un testimonio nítido de que los talentos se encuentran repartidos de forma homogénea, y que es la falta de oportunidades la que condena a miles de niños y jóvenes en nuestro país a vivir en la pobreza. No es posible que en el siglo XXI, ad portas de entrar en el desarrollo, Chile siga siendo un país donde el futuro de una persona esté marcado por la cuna. Estas vidas nos invitan a reflexionar sobre cómo estamos hoy distribuyendo las oportunidades y cómo a miles de niños y jóvenes los estamos condenando a la pobreza, simplemente porque no logramos asegurar las oportunidades que les permitan desarrollarse. La experiencia socialista, con todos sus errores y fracasos, nos muestra que esto se puede cambiar y se debe cambiar.

Por último, se echa de menos en el relato una investigación sobre las expectativas y visiones de mundo de estos jóvenes. Hubiese sido interesante que se indagara en cómo vivieron el régimen comunista soviético, qué pasó con sus percepciones, con sus visiones políticas, cuando conocieron en primera persona el paraíso soviético. El autor nos cuenta que una vez ocurrido el golpe un sentimiento de patriotismo y de querer liberar a Chile de la dictadura embargó a estos jóvenes. Pero, ¿cuánto duró este sentimiento? ¿No hubo acaso algunos, que al poco tiempo, se desembarcaron? Pérez les sigue la pista sólo a quienes estaban más comprometidos con la causa política, pero, ¿qué pasó con el resto? ¿No hubo desilusión por el proyecto socialista? ¿Era esto lo que ellos pensaban, por lo que ellos luchaban? El autor resalta los aspectos positivos del régimen soviético, como las oportunidades que tuvieron para continuar sus estudios en la universidad o en centros técnicos, que les permitieron seguir desarrollándose, pero, ¿cómo vivieron estos jóvenes la represión que existía en la Unión Soviética, la falta de libertad de prensa, de pensamiento, de movilización? ¿Se desvaneció, para algunos, el sueño socialista o, por el contrario, éste se fortaleció? 
Hubiera sido sumamente interesante saber qué piensan estas personas hoy del proyecto comunista. Ellos vivieron el sueño socialista en Chile, luego la realidad en la Unión Soviética; algunos conocieron regímenes democráticos como Alemania y Suecia, vivieron la caída del Muro de Berlín, la desintegración de la Unión Soviética y la derrota del proyecto comunista. ¿Qué piensan hoy? ¿Qué opinión tienen sobre el proceso de modernización que sufrió Chile, cómo ven los gobiernos de la Concertación? El texto no adentra en este aspecto, que hubiera sido sumamente interesante abordar.

Hoy estamos sumidos en una sociedad cada vez más individualista, en la que la apatía política es la manifestación de la apatía por el otro. La historia de estos jóvenes nos trae a la memoria el nostálgico recuerdo de una época en la cual las utopías tenían cabida, y lo colectivo imperaba por sobre lo individual. Se suele responsabilizar al régimen neoliberal o capitalista de la actual apatía, pero me pregunto si el estrepitoso fracaso de los regímenes socialistas y comunistas no habrá colaborado también a asentar esta desesperanza disfrazada de apatía. EP 